\title{
Experimental Study on Consolidation Characteristics of Compacted Loess
}

\author{
Jinhua Li (D), Songwei Zhao, Xiong Wang, Jiaqi Hao, Bin Zhi ${ }^{D}$, Hui Zhang, \\ and Botuan Deng \\ School of Architecture and Civil Engineering, Xi'an University of Science and Technology, Xi'an 710054, China \\ Correspondence should be addressed to Jinhua Li; 19731075@qq.com
}

Received 17 December 2020; Revised 30 January 2021; Accepted 26 May 2021; Published 7 June 2021

Academic Editor: Jian Xu

Copyright (C) 2021 Jinhua Li et al. This is an open access article distributed under the Creative Commons Attribution License, which permits unrestricted use, distribution, and reproduction in any medium, provided the original work is properly cited.

\begin{abstract}
The prediction of foundation settlement is an important topic in loess filling engineering. Based on a filled foundation in Yan'an, China, this study explores the consolidation characteristics of compacted loess with different compaction energy and consolidation pressure through consolidation tests, analyzes the strain-time curve and refines the curve within $2 \mathrm{~h}$, separates the primary and secondary consolidations, and obtains the critical time point between the primary and secondary consolidations. Deformation rate $S_{t}^{\prime}$ and cumulative deformation $S_{t}$ were introduced to analyze the $S_{t}^{\prime}-S_{t}$ curve at the secondary consolidation stage; the secondary consolidation coefficient was employed to describe the secondary consolidation characteristics of compacted loess. According to the secondary consolidation characteristics, a prediction model of loess settlement considering different compaction energy and fill thickness was proposed, and the applicability of the model was further analyzed. The model will facilitate in guiding the design and construction of loess filling engineering.
\end{abstract}

\section{Introduction}

With the progress of China's west development strategy and the improved urbanization level, construction land in western loess area has become increasingly limited, and thus, a large number of loess filling projects have appeared. The height of some filling works exceeds $100 \mathrm{~m}$. Correspondingly, engineering problems related with filling projects have drawn more attention, such as ground and wall cracking (Figure 1) caused by uneven settlement of the foundation. In addition to the deformation of the filling body during the construction stage, the filling foundation continues to produce secondary consolidation deformation under high dead weight stress after completion. Its subsidence often lasts for several years or even decades and has become an important factor affecting the safety of engineering construction and economic development in the western loess area. Thus, investigation on the postconstruction settlement prediction of high-fill loess foundations has become an important topic in foundation stability research.

As for research on secondary consolidation, many experiments and numerical calculations have been conducted in recent decades [1-3]. Some scholars have investigated on the influence of stress history, loading ratio, and loading time on the secondary consolidation coefficient [4-6]. In terms of prediction for postconstruction settlement of high fills, the current focus is mostly on new models and methods. Mei and Yin [7] established a settlement-time relationship curve that can consider instantaneous settlement, consolidation settlement, and secondary consolidation settlement according to the characteristics of settlement under instantaneous loading. Based on the Cambridge model, Yin et al. [8] proposed a simple elastoviscoplastic model that can simulate the aging characteristics of soft soil. Some researchers have focused on the secondary consolidation deformation of high filling soil, but the results differ greatly. Taylor and Merchant [9] proposed that the secondary consolidation compression of a consolidation test is plastic adjustment of the clay structure. Newland and Allely [10] thought the secondary consolidation coefficient was unrelated to consolidation pressure. Mesri and Godlewski [11] believed that the coefficient was unrelated to the incremental ratio of load and was determined by the final consolidation 


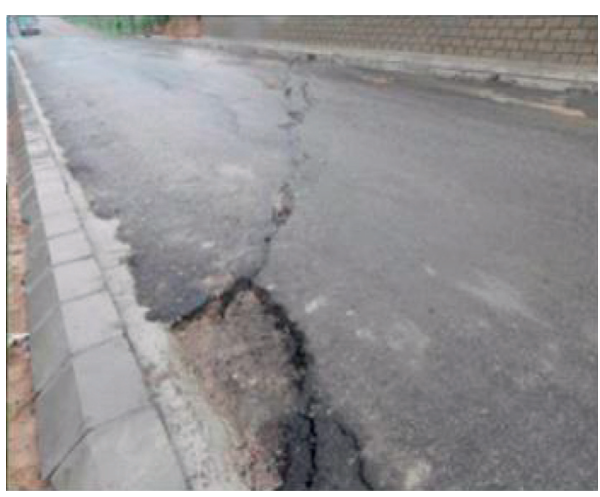

(a)

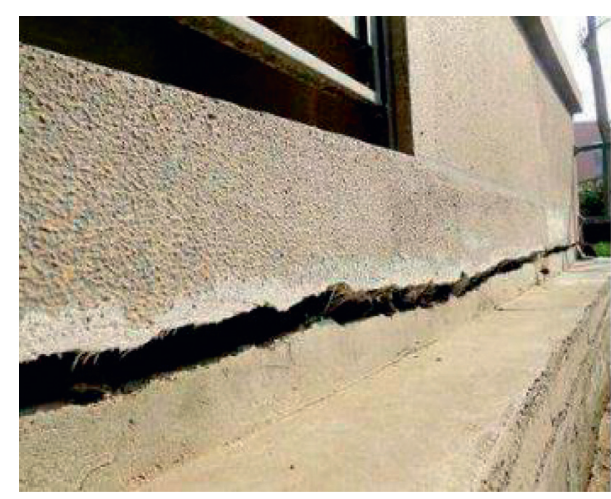

(b)

FIgURE 1: Secondary disasters caused by uneven settlement of foundation after fill engineering. (a) Road cracking caused by subgrade settlement of the high-fill section. (b) Wall cracking caused by uneven foundation settlement.

pressure. Yin et al. [4] showed that the secondary consolidation coefficient changed with time and was determined by the consolidation pressure, load incremental ratio, and surcharge preloading, based on experimental results in the laboratory. Leroueil et al. [12] found that under the same level of load, the secondary consolidation coefficient was not a constant value, but reached the maximum value when near the initial consolidation pressure and decreased with time. Alonso et al. [13] proposed an empirical formula for calculating the secondary consolidation settlement after construction by analyzing the results of field preloading and remodeling compression tests; they believed that the secondary consolidation coefficient was an over consolidation ratio function unrelated to time. Through theoretical analysis of Bjerrum creep diagrams, Nash [14] considered that the secondary consolidation coefficient of over-consolidated soil increased gradually with time and finally tended to a constant value. This research showed that the study of high fill soil is complex. Soil is a complex porous three-phase material in which many phenomena take place simultaneously. Due to the complexity, many soil mechanics problems must be solved numerically or by laboratory investigation [15]. Ge et al. [16] conducted a one-dimensional consolidation creep test on remolded loess; they analyzed the degree of compaction, moisture content, and vertical pressure, and found them to be important factors affecting the secondary consolidation characteristics of loess. Xu et al. [17-19] conducted laboratory tests on loess and studied related deformation influencing factors. Nash et al. [20] conducted one-dimensional consolidation tests to study the influence of depth and strain rate on yield stress, creep, and anisotropy during compression of Bothkennar clay. Augustesen et al. [21] summarized previous experimental studies on the creep properties of soft clay, limited to onedimensional and triaxial conditions; there are some unreasonable aspects, such as the confusion between structural soil and remolded soil.

For high-fill projects, the secondary consolidation under the action of its own weight after the completion of the fill requires a long time to stabilize. Thus, the analysis of secondary consolidation is of importance to the long- term stability of a fill project. In this study, an indoor onedimensional consolidation test was performed on compacted loess, and the effects of compaction energy and consolidation pressure on the secondary consolidation characteristics of compacted loess were studied. A settlement prediction model considering compaction energy and fill thickness was proposed, and its applicability was analyzed.

\section{One-Dimensional Consolidation Tests}

2.1. Soil Properties. The test loess was sampled from a fill project in Yan'an of northern Shanxi province, at a depth of $3 \mathrm{~m}$. The basic physical properties are presented in Table 1.

2.2. Confirmation of Compaction Energy. To systematically investigate the impact of compaction energy and consolidation pressure on the consolidation characteristics of loess, the construction technology of dynamic compaction in a high-fill project in the loess area was studied, according to four kinds of single tamping energy that are widely used in engineering. A similar coefficient was used to determine the corresponding indoor test tamping energy. An indoor compaction test was conducted on the remolded loess, and the water content of the sample was controlled at the optimal water content.

This study considers four construction parameters: single tamping energy $E$, the weight of the rammer $W$, the diameter of the rammer $D$, and the soil parameters (dry density, $\gamma_{d}$ ). The specific process is described as follows:

Set the depth of the ramming pit as $H$; then,

$$
F\left(E, W, D, \gamma_{d}, H\right)=0 .
$$

In equation (1), there are five physical quantities: $E, W$, $D, \gamma_{\mathrm{d}}$, and $H$. $W$ and $D$ are selected as the basic dimensions. According to Buckingham's theorem ( $\pi$ theorem), $\pi$ number is three; through dimensional analysis of the three remaining physical quantities, three dimensionless $\pi$ numbers are obtained as 
TABle 1: Physical properties of the test loess.

\begin{tabular}{|c|c|c|c|c|c|c|c|}
\hline \multirow{2}{*}{$\begin{array}{l}\text { Natural } \\
\text { moisture } \\
\text { content } \omega(\%)\end{array}$} & \multirow{2}{*}{$\begin{array}{l}\text { Limit of } \\
\text { liquidity } \omega_{l} \\
\text { (\%) }\end{array}$} & \multirow{2}{*}{$\begin{array}{c}\text { Limit of } \\
\text { plasticity } \omega_{p} \\
(\%)\end{array}$} & \multirow{2}{*}{$\begin{array}{c}\text { Index of } \\
\text { plasticity } I_{p}\end{array}$} & \multirow{2}{*}{$\begin{array}{l}\text { Relative } \\
\text { density of } \\
\text { soil }\end{array}$} & \multicolumn{3}{|c|}{ Grain composition (\%) } \\
\hline & & & & & $\begin{array}{c}\text { Sand grain } \\
0.25-0.075(\mathrm{~mm})\end{array}$ & $\begin{array}{l}\text { Powder particles } \\
0.075-0.005(\mathrm{~mm})\end{array}$ & $\begin{array}{l}\text { Clay particles } \\
<0.005(\mathrm{~mm})\end{array}$ \\
\hline 7.84 & 33 & 20 & 13 & 2.70 & 2.78 & 73.06 & 24.16 \\
\hline
\end{tabular}

$$
\begin{aligned}
& \pi_{1}=\frac{E}{W D}, \\
& \pi_{2}=\frac{D^{3} \gamma_{d}}{W}, \\
& \pi_{3}=\frac{H}{D} .
\end{aligned}
$$

Substituting equation (2) into equation (1), we obtain

$$
F\left(\frac{E}{W D}, \frac{D^{3} \gamma_{d}}{W}, \frac{H}{D}\right)=0 .
$$

According to the similarity principle, the similarity condition can be obtained from equation (3).

$$
F\left(\frac{E}{W D}, \frac{D^{3} \gamma_{d}}{W}, \frac{H}{D}\right)=0,
$$

where $C$ is the similarity coefficient of each construction parameter (subscript).

In practical engineering, the main indicator of quality inspection after compaction is $\gamma_{d}$. To reflect the actual construction conditions based on the indoor test, let the similarity coefficient $C \gamma_{d}=1$. According to equation (4), the similarity coefficient of each process parameter in the indoor test can be determined as

$$
\begin{aligned}
& C_{w}=1: 8000, \\
& C_{D}=1: 20, \\
& C_{E}=1: 160000, \\
& C_{\gamma_{d}}=1: 1 .
\end{aligned}
$$

Using the similarity coefficient to compare the hammer weight and the diameter of the rammer and the following equation, the compaction energy corresponding to the indoor test can be obtained.

$$
E=\frac{G h N n}{V},
$$

where $E$ is the compaction energy, $\mathrm{kJ} / \mathrm{m}^{3} ; G$ is the tamper gravity, $\mathrm{kN}$; $h$ is the tamper drop height, $\mathrm{m} ; N$ is the number of ramming times; $n$ is the number of rammed soil layers; $V$ is the effective rammed soil volume, $\mathrm{m}^{3}$.

2.3. Specimen Preparation. To systematically study the impact of compaction energy on the consolidation characteristics of loess, the moisture content of the sample is controlled at the optimal moisture content. The specific steps are described as follows.
(1) Determination of optimum moisture content: remolding soil samples were prepared using the compaction method in geotechnical test method standard (GB/T50123-2019); the optimum moisture content corresponding to each compaction energy was determined by an indoor light compaction test, as given in Table 2 .

(2) Preparation of optimal moisture content: the soil water after sieving and air drying was prepared at the optimal moisture content, as given in Table 2 .

(3) Preparation of consolidated samples: the remolded soil samples from the indoor light compaction test were demolded and cut according to the standard to make cylindrical consolidated samples, with a size of $50 \mathrm{~cm}^{2} \times 2 \mathrm{~cm}$.

2.4. Test Plan. A one-dimensional consolidation test was conducted on the soil after compaction of different grades. Test schemes were selected with final consolidation pressure levels of 500,1000,1500, and $2000 \mathrm{kPa}$ and compaction energies of $E_{0}=592.2 \mathrm{~kJ} / \mathrm{m}^{3}$ (standard light compaction test energy), $\quad E_{1}=743.8 \mathrm{~kJ} / \mathrm{m}^{3}, \quad E_{2}=1420.8 \mathrm{~kJ} / \mathrm{m}^{3}, \quad$ and $E_{3}=2169.0 \mathrm{~kJ} / \mathrm{m}^{3}$. A total of 16 groups of consolidation tests were conducted to study the consolidation deformation of remolded soil samples.

The standard consolidation test was conducted according to the Standard for Geotechnical Test Methods GB/T50123-2019. The specific steps are described as follows:

(1) The test used the WG single-lever consolidation instrument and a dial gauge to read the data

(2) To ensure good contact between the sample and the loading system, the soil sample was preloaded and stabilized at $25 \mathrm{kPa}$

The soil sample was preloaded and stabilized at $25 \mathrm{kPa}$ according to $(0 \longrightarrow 25 \longrightarrow 50 \longrightarrow 100 \longrightarrow 200$ $\longrightarrow 500 \mathrm{kPa}, \quad 0 \longrightarrow 25 \longrightarrow 50 \longrightarrow 100 \longrightarrow 200 \longrightarrow 400$ $\longrightarrow 1000 \mathrm{kPa}, 0 \longrightarrow 25 \longrightarrow 50 \longrightarrow 100 \longrightarrow 200 \longrightarrow 400$ $\longrightarrow 800 \longrightarrow 1500 \mathrm{kPa}$, and $0 \longrightarrow 25 \longrightarrow 50 \longrightarrow 100 \longrightarrow$ $200 \longrightarrow 400 \longrightarrow 800 \longrightarrow 1600 \longrightarrow 2000 \mathrm{kPa})$ for gradual loading. Table 2 provides only the final consolidation pressure at all loading levels. The stability standard of this test refers to a previous study [22]; the stability standard of loading was that the vertical cumulative deformation after $24 \mathrm{~h}$ was less than $0.002 \mathrm{~mm}$.

(3) During the test, a wet towel was used to wrap the sample to prevent the evaporation of moisture and ensure that the moisture content did not change over time 
TABLE 2: Consolidation pressure and stability standards.

\begin{tabular}{lccc}
\hline Compaction energy $\left(\mathrm{kJ} / \mathrm{m}^{3}\right)$ & Optimal moisture content $(\%)$ & Final consolidation pressure $(\mathrm{kPa})$ & Stability standard $(\mathrm{mm} / \mathrm{d})$ \\
\hline 592.2 & 16.68 & $500,1000,1500,2000$ & 0.002 \\
743.8 & 16.15 & $500,1000,1500,2000$ & 0.002 \\
1420.8 & 14.37 & $500,1000,1500,2000$ & 0.002 \\
2169.0 & 13.54 & $500,1000,1500,2000$ & 0.002 \\
\hline
\end{tabular}

(4) In measuring the sedimentation rate, the reading of the meter should be measured according to the time after pressurization until it is stable

(5) The secondary consolidation settlement test can be continued after the primary consolidation test is completed, until the consolidation is stable

2.5. Analysis of Test Results. Figures 2 and 3 show the consolidation tests of specimens with different compaction energy and consolidation pressure in different schemes and plots of the strain-time $(\varepsilon-t)$ curves. For simplicity, only the final loading consolidation strain curve of the sample in the four-stage loading scheme is included (500, 1000, 1500, and $2000 \mathrm{kPa}$ ). The zero point of the strain curve is the stable strain value before stage loading. The strain curve has the same trend. The deformation rate of the specimen is greater at the instant of each level of loading; with time, the deformation rate gradually decreases and tends to stabilize; the vertical strain increases with an increase in the vertical stress. Comparing Figures 2(a)-2(d), 3(a)-3(d), and the $\varepsilon$ - $t$ curves with four compaction energies, it is found that when the sample has the optimal moisture content, as the compaction energy increases, the vertical strain of the specimen with the same vertical stress gradually decreases. Considering $1500 \mathrm{kPa}$ as an example, the stable vertical strain is $6.38 \%$ in response to compaction energy of $592.2 \mathrm{~kJ} / \mathrm{m}^{3}$; with respect to compaction energy of $743.8 \mathrm{~kJ} / \mathrm{m}^{3}$, the stable vertical strain is $6.10 \%$; as for the compaction energy of $1420.8 \mathrm{~kJ} / \mathrm{m}^{3}$, the stable vertical strain is $5.41 \%$; and in the case of compaction energy of $2169.0 \mathrm{~kJ} / \mathrm{m}^{3}$, the stable vertical strain is $5.36 \%$. Based on the test data analysis, greater compaction produces a smaller gap between the soil particles and less free water, encouraging the spread of soil particle peristalsis, corresponding to a thinner film, great mutual attraction between the soil particle molecules, resilience, and little deformation.

2.6. Separation of Primary and Secondary Consolidations. Much research has been conducted on the mechanism and division of primary and secondary consolidations. It was believed that the high fill of loess is generally unsaturated soil, which is different from the drainage consolidation of saturated soil. Unsaturated soil is a three-phase body composed of a soil skeleton, water, and gas. Under the action of the overburden, the gas between the pores of the soil particles is discharged first. With the continuous action of the load, the gas is gradually exhausted, and there is only water between the pores of the soil particles. At this time, it can be considered that the soil has developed from unsaturated soil to saturated soil, and the load continues to act. After the drainage consolidation of saturated soil, i.e., the completion of primary consolidation, the soil particles are adjusted under the constant effective stress, such that the volume of the soil continues to decrease; this is the secondary consolidation process.

The traditional view involved in the division of primary and secondary consolidations is that secondary consolidation occurs after the completion of primary consolidation [23]; another view is that when the upper soil layer is loaded, the main consolidation and secondary consolidation occur simultaneously. With the main consolidation process completed, the secondary consolidation initiates [4].

This study employs the separation method of primary and secondary consolidations proposed in the literature [24], introduces the deformation rate $S_{t}{ }_{t}$ and the cumulative deformation parameter $S_{t}$ in the secondary consolidation process, and proves that the $S_{t}^{\prime}-S_{t}$ relationship in the secondary consolidation stage can be fitted with a straight line, which determines the secondary consolidation coefficient, as shown in the following equation.

$$
C_{\alpha}=\frac{\Delta e}{\Delta \lg t} .
$$

The specific separation method is described as follows. According to the one-dimensional consolidation test, the settlement rate-settlement volume relationship curve $S_{t}^{\prime}-S_{t}$ can be obtained, as shown in Figure 4. From this curve, it is observed that in the initial stage of loading, the $S_{t}^{\prime}-S_{t}$ curve is steep and the soil sample has a large deformation rate. This section represents the deformation caused by the transient unsaturated soil exhaust after loading. The curve suddenly slows, an inflection point appears, and the deformation rate suddenly decreases. It is considered that this is the primary consolidation stage, and the curve continues to extend. After the primary consolidation stage, the curve further slows and a second inflection point appears. This stage can be considered as a secondary consolidation stage. There are short primary and secondary consolidation sections. Considering the intersection of the primary and secondary consolidation time periods appearing in the $S_{t}^{\prime}-S_{t}$ relationship curve as the boundary between the primary and secondary consolidation, after determining the primary and secondary boundary time points, the curve segment after the boundary point in the strain-time curve is used to establish the $e-$ $\lg (t)$ curve. According to equation (7), the slope of the curve is the secondary consolidation coefficient $C_{\alpha}$.

In this study, the strain-time curve obtained in the onedimensional consolidation test is refined, and the strain-time curve within $2 \mathrm{~h}$ can be obtained. Considering the $S_{t}^{\prime}-S_{t}$ curve (Figure 5) and the strain-time curve (Figure 6) with the standard light compaction energy $E_{0}=592.2 \mathrm{~kJ} / \mathrm{m}^{3}$ and 


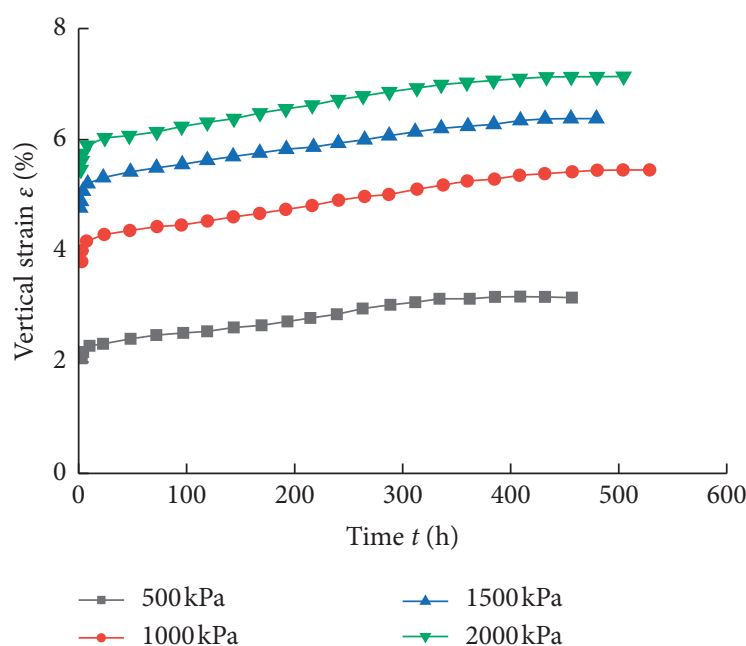

(a)

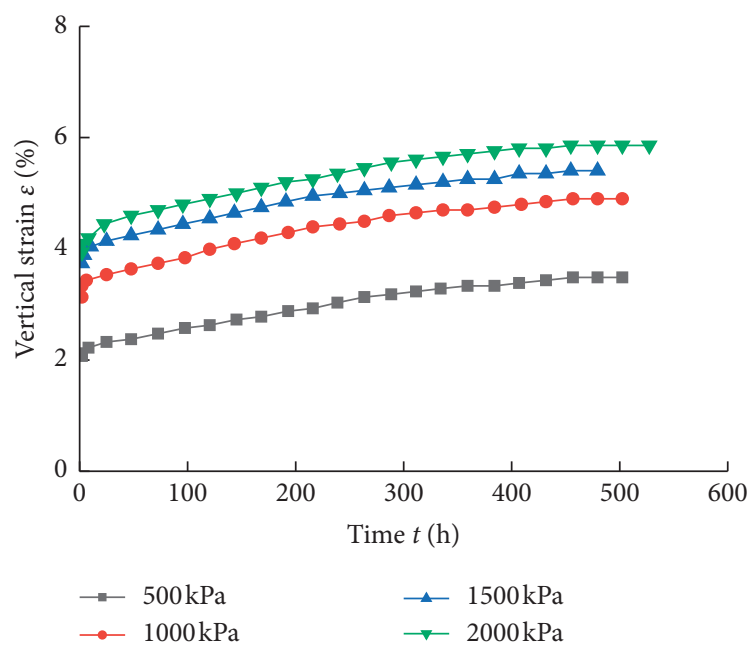

(c)

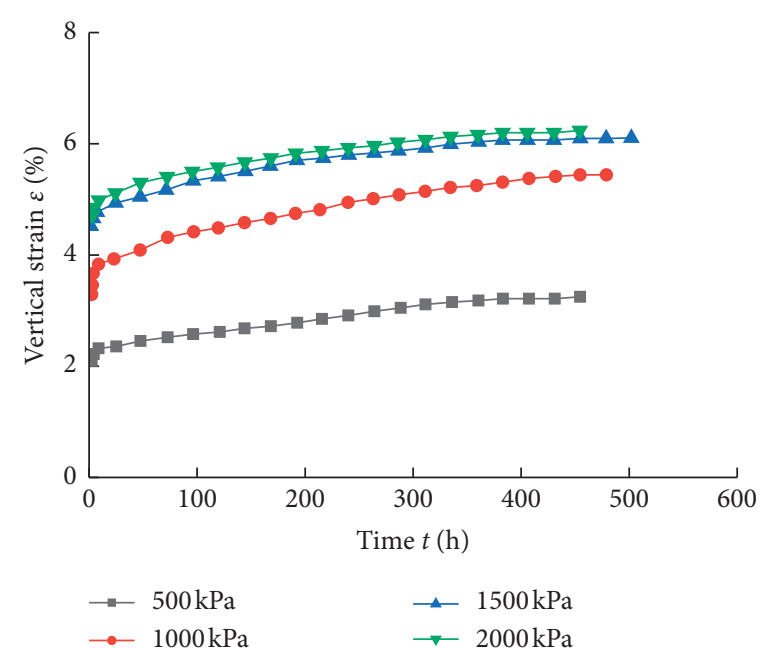

(b)

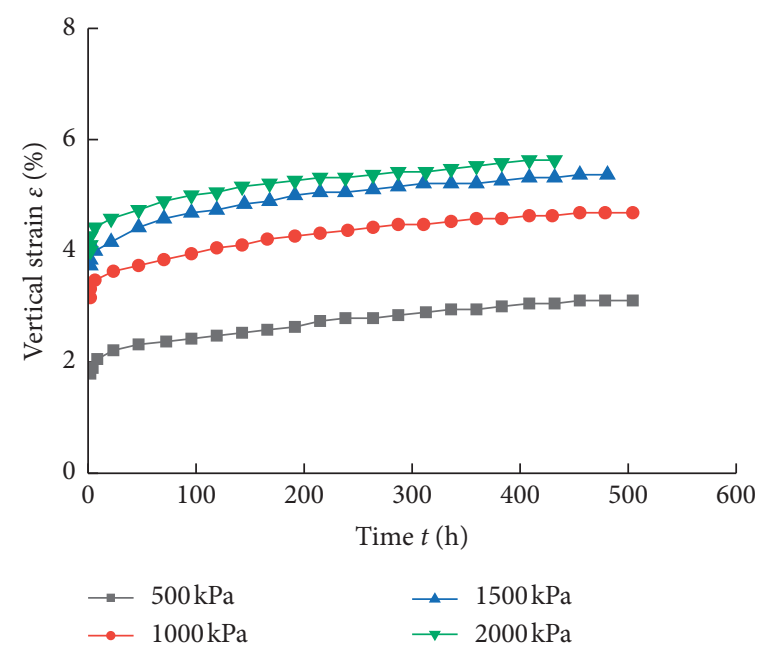

(d)

Figure 2: Strain-time curve with different compaction energies and vertical stress. (a) $E_{0}=592.2 \mathrm{~kJ} / \mathrm{m}^{3}$. (b) $E_{1}=743.8 \mathrm{~kJ} / \mathrm{m}^{3}$. (c) $E_{2}=1420.8 \mathrm{~kJ} / \mathrm{m}^{3}$. (d) $E_{3}=2169.0 \mathrm{~kJ} / \mathrm{m}^{3}$.

$\sigma=1500 \mathrm{kPa}$ as examples, the primary consolidation stage, the overlapping stage of primary and secondary consolidations, and the secondary consolidation stage can be distinguished, and the time point of the boundary between primary and secondary consolidation can be obtained. After determining the time point of the primary and secondary boundaries, the curve segment after the boundary point in the strain-time curve was used to establish the $e-\lg (t)$ curve, as shown in Figure 7. According to equation (7), the slope of the curve is the secondary consolidation coefficient $C_{\alpha}$. The secondary consolidation coefficient reflects the consolidation speed of the soil. A greater secondary consolidation coefficient indicates more obvious secondary consolidation characteristics of the soil. Based on this method, the strain-time curves with different compaction energies and vertical loads can be separated into primary and secondary consolidation, and the dividing time points of primary and secondary consolidation can be obtained for all samples. The dividing time points of primary and secondary consolidation for all samples are at approximately 39 60 $\mathrm{min}$.

In accordance with the curve trends in Figures 5 and 6 , it is found that the loess deforms instantaneously at the moment of loading, the deformation rate gradually decreases with time, and the final deformation rate essentially stabilizes, but there is still a slight deformation over time. The rule of the entire deformation process is reflected by the change in deformation rate from the main consolidation stage to the secondary consolidation stage. Comprehensive analysis on the curve characteristics can be understood as follows: after the unsaturated test soil sample is subjected to vertical load, the volume between the pores is compressed by compaction, resulting in a relatively obvious initial strain; as time continues, the pores are gradually compacted, and the soil body structure is broken; the particles move with each other, the friction between the particles increases, and the soil particles gradually reach relative stability. 


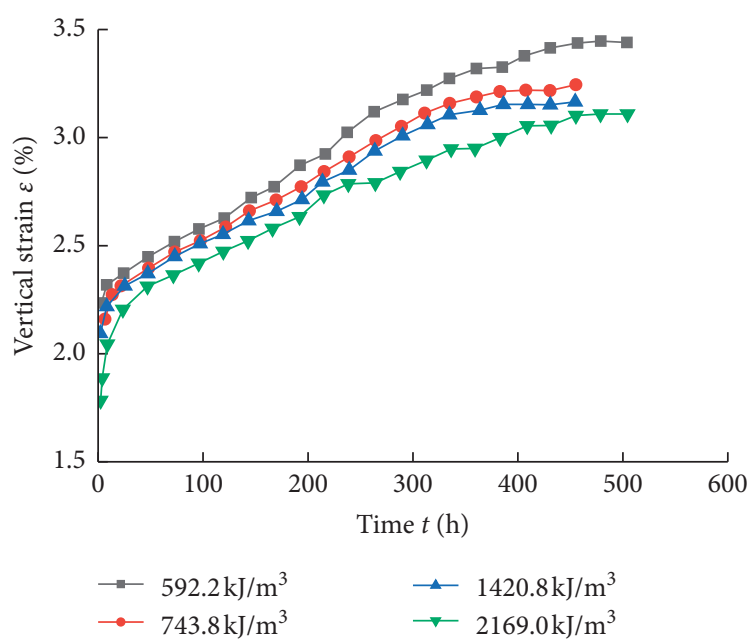

(a)

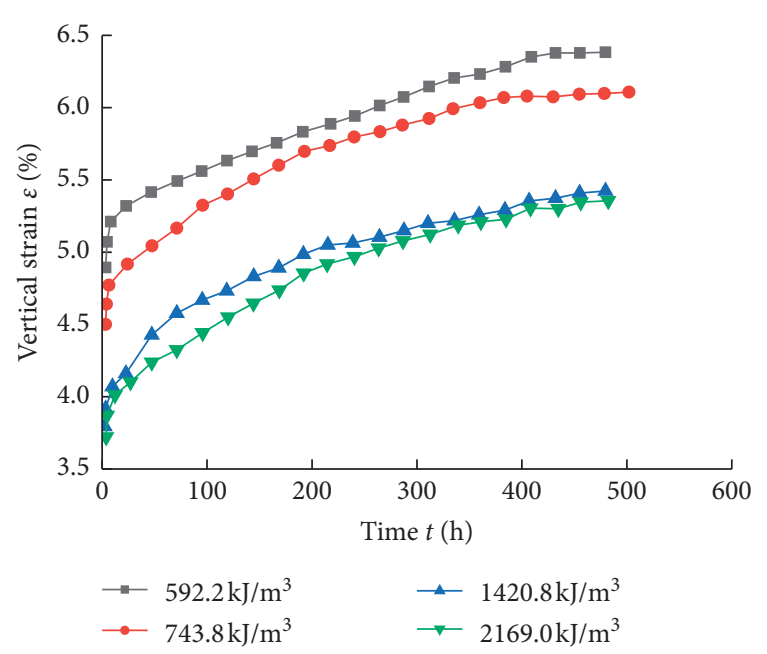

(c)

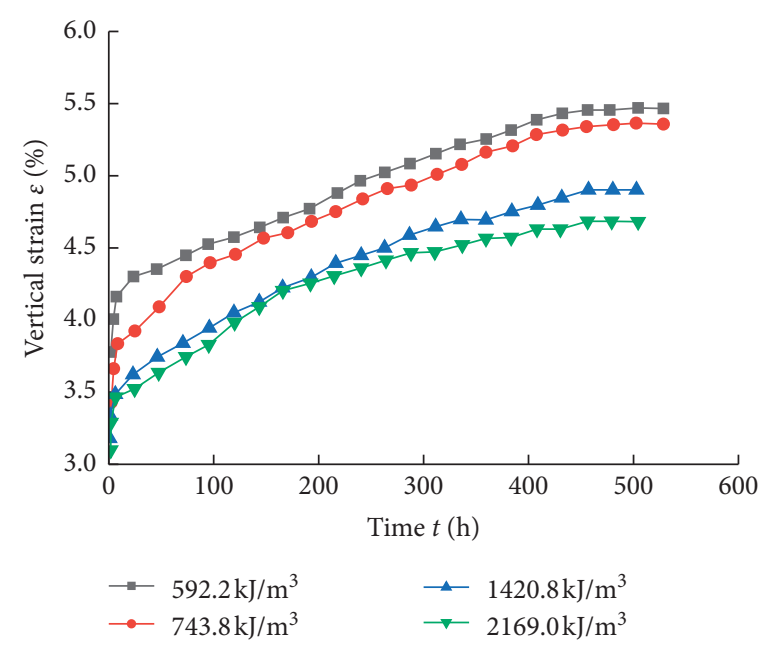

(b)

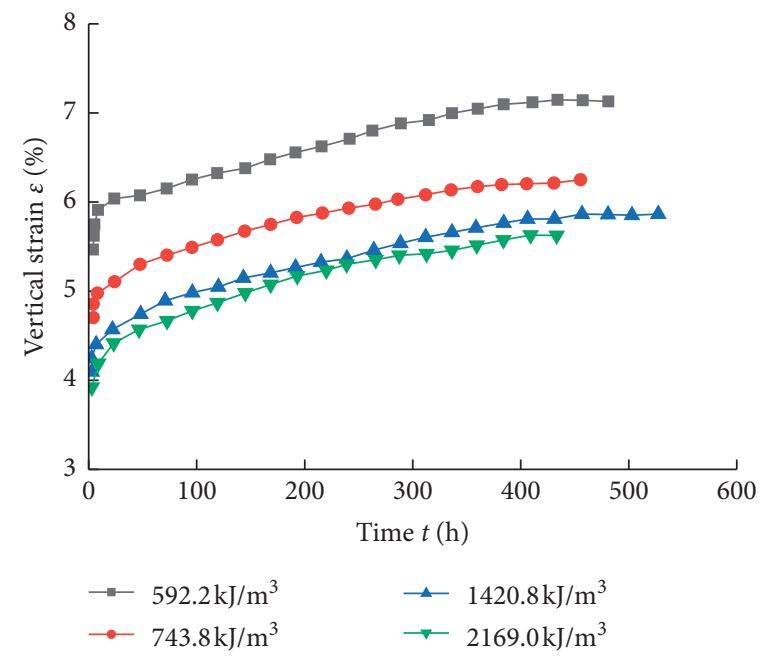

(d)

FiguRE 3: Strain-time curve with different vertical stress and compaction energies. (a) Vertical stress $\sigma=500 \mathrm{kPa}$. (b) Vertical stress $\sigma=1000 \mathrm{kPa}$. (c) Vertical stress $\sigma=1500 \mathrm{kPa}$. (d) Vertical stress $\sigma=2000 \mathrm{kPa}$.

According to equation (7) and the relationship curve of the secondary consolidation coefficient with different compaction energies shown in Figure 8, for the same compaction energy, the secondary consolidation coefficient $C_{\alpha}$ increases with an increase in vertical stress. With an increase in compaction energy, the influence of vertical stress on the secondary consolidation coefficient gradually decreases. When the vertical stress is constant, with an increase in compaction energy under a greater load, the secondary consolidation coefficient $C_{\alpha}$ exhibits a decreasing trend that is not obvious because the consolidation samples were prepared with an optimal water content corresponding to different compaction energies. The three-phase state of soil is complex, and the smaller vertical stress is not sufficient to overcome the viscosity of the soil and the friction between the particles, demonstrating that the effect of compaction energy and consolidation pressure on the secondary consolidation coefficient is small. However, under a greater vertical stress, the secondary consolidation coefficient increases gradually and decreases with an increase in the compaction energy.

The analysis shows that compaction energy and consolidation pressure have a great influence on the secondary consolidation of compacted loess. In actual projects, in order to control the postconstruction settlement of loess high-fill bodies, the construction compaction energy should be fully considered. Due to the high sensitivity of the secondary consolidation coefficient of compacted loess to compaction energy with high stress levels, it should be carefully considered in higher loess-fill projects.

\section{Settlement Prediction Model}

Based on the inflection time points between the primary and secondary consolidations, the starting point of the secondary consolidation was determined. After data processing, the relationship curves of $\ln (\varepsilon / t)$ and $\ln (t)$ can be obtained for different compaction energies with different vertical stress $\sigma$ 


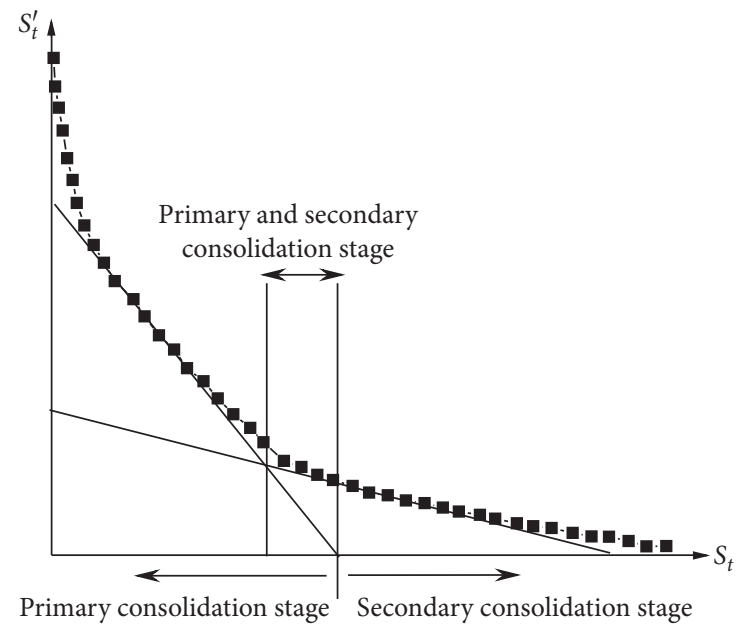

FIGURE 4: Relationship between settlement volume and settlement rate.

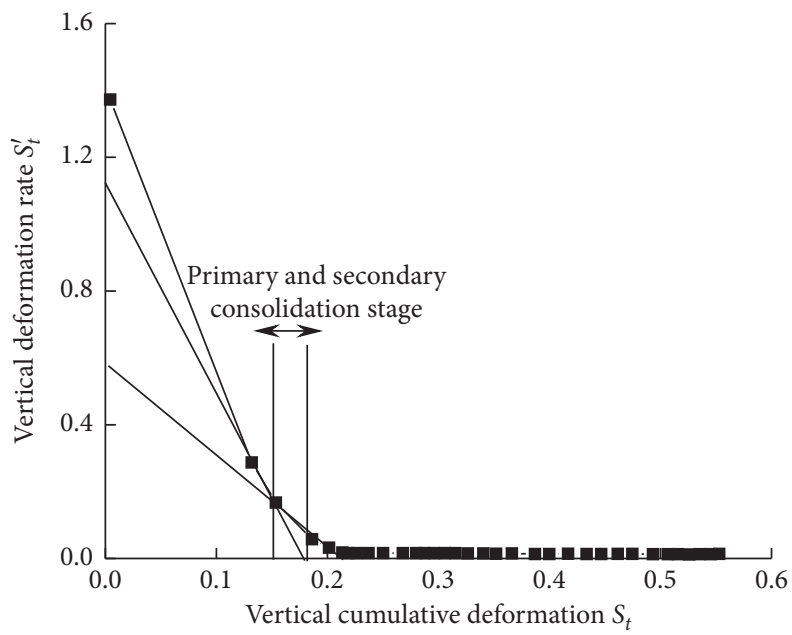

Figure 5: $S_{t}^{\prime}-S_{t}$ curve at $E_{0}=592.2 \mathrm{~kJ} / \mathrm{m}^{3}$ and $\sigma=1500 \mathrm{kPa}$.

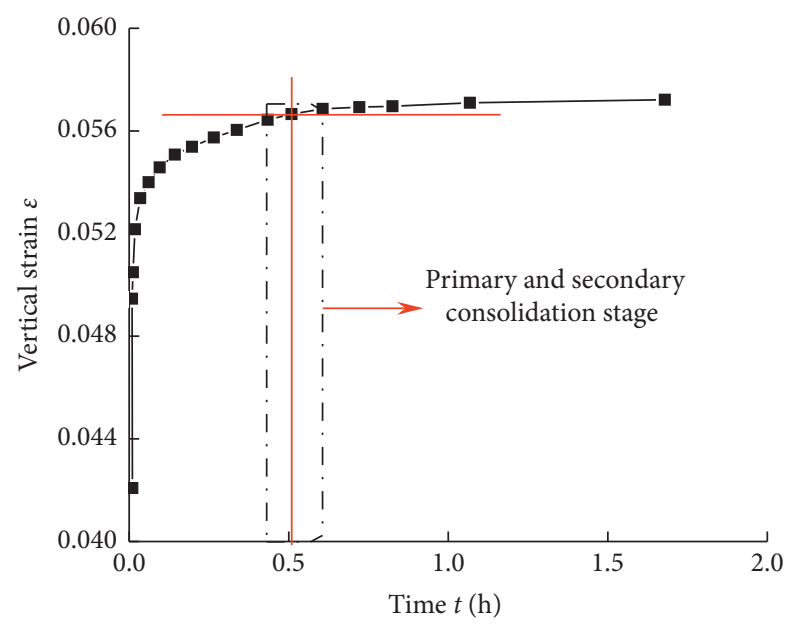

Figure 6: Strain-time curve at $E_{0}=592.2 \mathrm{~kJ} / \mathrm{m}^{3}$ and $\sigma=1500 \mathrm{kPa}$. 


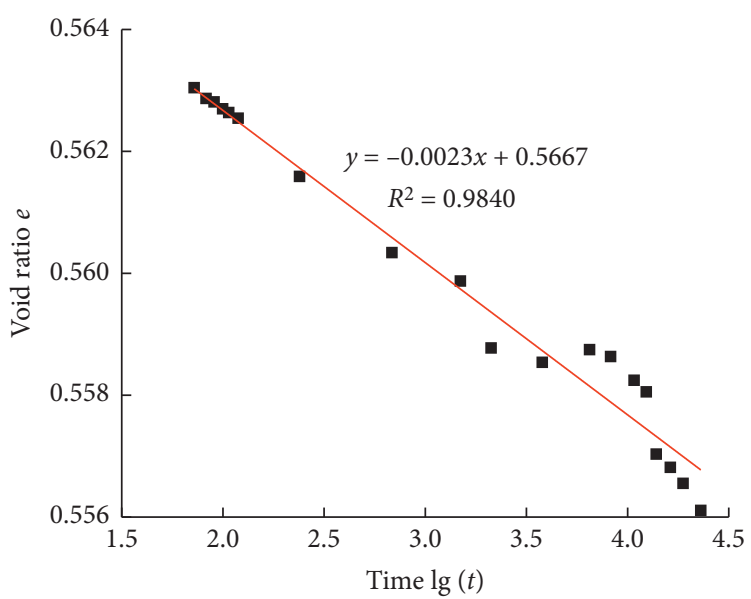

FIgURE 7: $e-\lg (t)$ curve at $E_{0}=592.2 \mathrm{~kJ} / \mathrm{m}^{3}$ and $\sigma=1500 \mathrm{kPa}$.

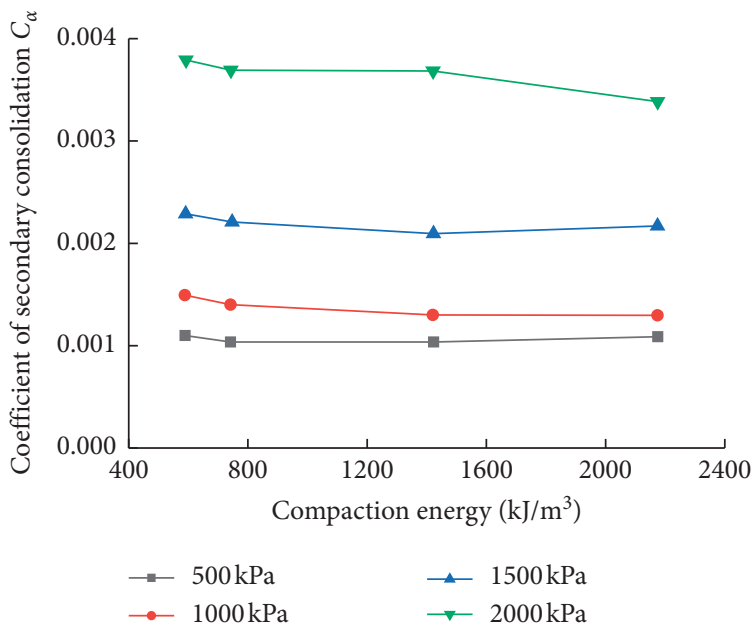

FIGURE 8: Coefficient of secondary consolidation with different compaction energies.

at the secondary consolidation stage of the specimen. This study uses $E_{3}=2169.0 \mathrm{~kJ} / \mathrm{m}^{3}$ as an example, as shown in Figure 9.

It is observed in Figure 9 that $\ln (\varepsilon / t)$ and $\ln (t)$ have a good linear relationship, expressed as

$$
\ln \left(\frac{\varepsilon}{t}\right)=a \ln (t)+b
$$

In equation (8), $a$ and $b$ are the undetermined coefficients. In Figure 9, with different compaction energies and different vertical stress conditions, the curve slope $a$ exhibits a small range, and $a=-0.9538$. Intercept $b$ changes with the vertical stress $\sigma$. Figure 10 shows the change rule of intercept $b$ with the vertical stress $\sigma$ in response to the compaction energy of $E_{3}=2169.0 \mathrm{~kJ} / \mathrm{m}^{3}$.

In Figure 10, the change in $b$ with the vertical stress $\sigma$ conforms to an exponential relationship, expressed as

$$
b=c \ln (\sigma)+b .
$$

Substituting equation (9) into equation (8), with $a=-0.9538$, the model expression describing the secondary consolidation deformation characteristics of loess with different compaction energies can be obtained, as shown in the following equation:

$$
\varepsilon(t)=\sigma^{c} e^{d} t^{0.0462} .
$$

$\varepsilon(t)$ is the strain value at any moment, $\sigma$ is the vertical stress, $t$ is the time, and $c$ and $d$ are indicated in Table 3 .

To obtain the partial derivative of time $t$ on both sides of equation (10), the relationship between strain rate and time can be obtained:

$$
\bar{\varepsilon}(t)=0.0462 \sigma^{c} e^{d} t^{-0.9538} .
$$

Equation (11) reflects the relationship between the strain rate $\bar{\varepsilon}$ and the time $t$. As $t$ increases, the strain rate gradually decreases; the strain rate eventually approaches 0 , which is consistent with actual engineering.

\section{Model Validation}

To verify the feasibility of equation (10), the same time point was employed to calculate the compaction energy and the strain under different loads, and the results were compared 


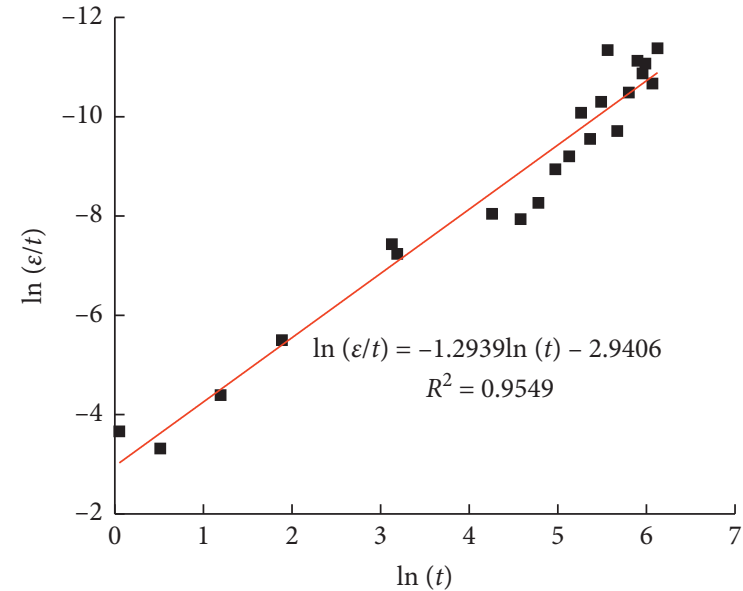

(a)

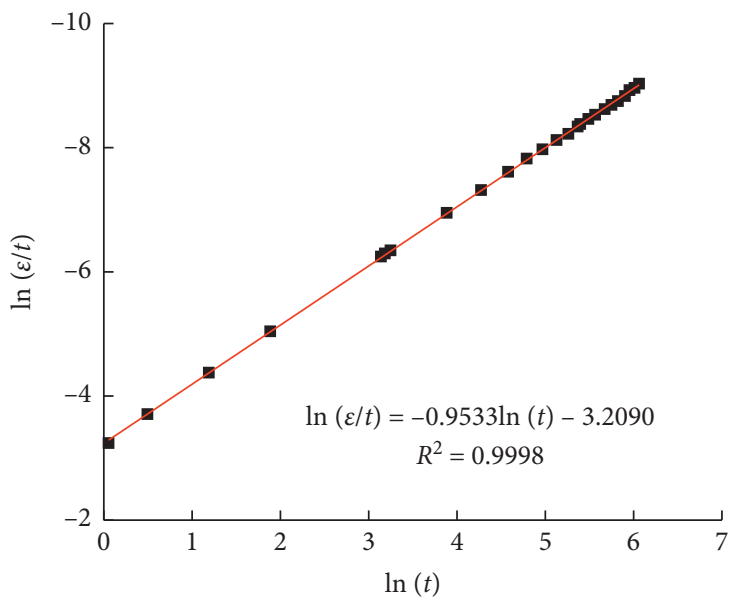

(c)

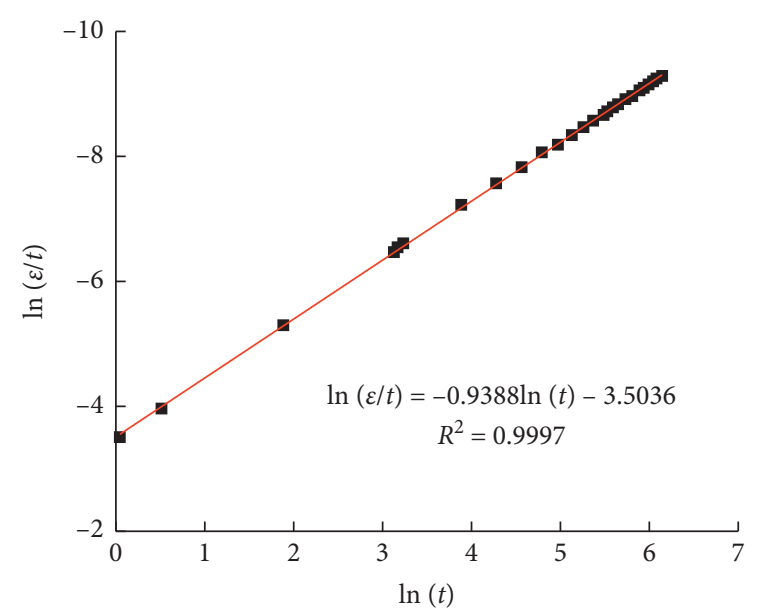

(b)

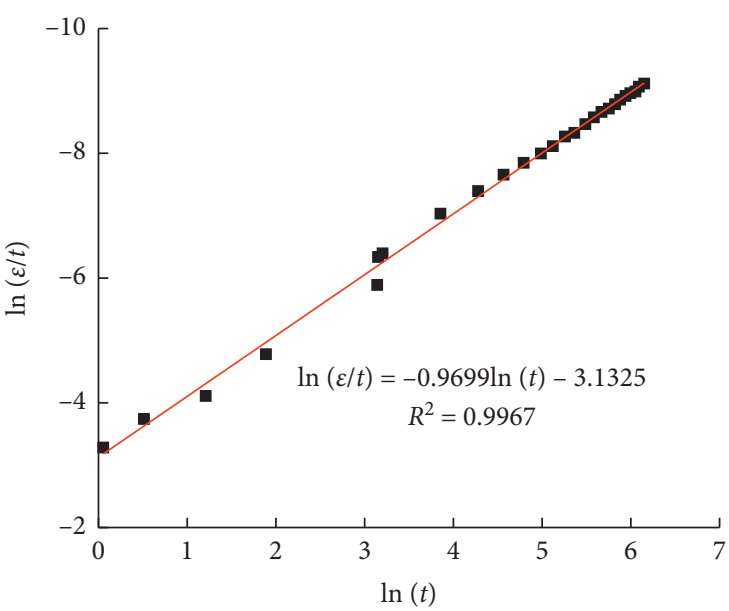

(d)

Figure 9: $\ln (\varepsilon / t)-\ln (t)$ curve at $E_{3}=2169.0 \mathrm{~kJ} / \mathrm{m}^{3}$. (a) Vertical stress $\sigma=500 \mathrm{kPa}$. (b) Vertical stress $\sigma=1000 \mathrm{kPa}$. (c) Vertical stress $\sigma=1500 \mathrm{kPa}$. (d) Vertical stress $\sigma=2000 \mathrm{kPa}$.

with the test results. To intuitively understand the difference between the calculation and test results, the results with different compaction energies are investigated. The points in Figure 11 represent the data obtained from the test, and the curve represents the strain-time curve under different vertical loads on the basis of prediction formula; it is stipulated that the strain value at $t=0$ is the stable strain before the loading process.

It is observed in Figure 11 that equation (10) can best describe the changing trend of the loess sample in the test, indicating that the strain rate is relatively large in the initial stage of the test; with the elapse of time, the strain rate decreases and eventually stabilizes.

With a lack of relevant actual field monitoring results, it is found by comparing the predicted results with the test results that the model prediction results are slightly greater than the experimental results in the early stage; the deviation decreases gradually with time, and the curves tend to coincide. From analysis of this experiment, the main reasons for the deviation are the test soil specimens were prepared at the optimal moisture content corresponding to different compaction energies, and the relative position arrangement between soil particles was complex. At the beginning of loading, when the soil sample was subjected to vertical consolidation pressure, the volume between pores was compressed, the particles moved mutually, and the relative position changed. The soil specimen was in the complex state of solid-liquid-gas three-phase coupling, the stress-strain relationship of the soil was complex, and there was no regularity. Thus, the prediction results of the model obtained by the fitting of the secondary consolidation curve were greater than those in the initial stage of the test. Through comparative analysis of the model prediction and test data, the prediction model proposed in this study can accurately describe the consolidation strain development trend in the loess laboratory test and is suitable for predicting the long-term postconstruction settlement of loess filling. 


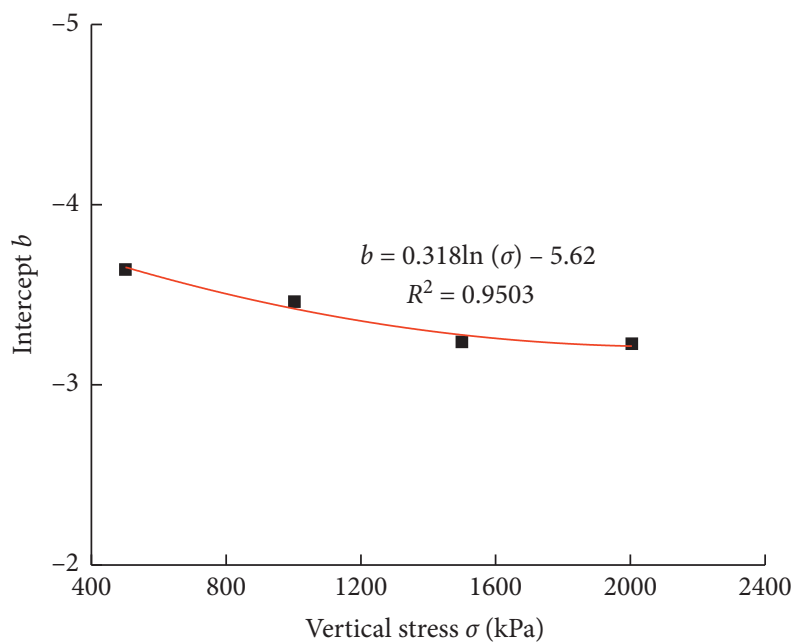

FIgURE 10: Relationship between intercept $b$ and vertical stress $\sigma$.

TABLe 3: Parameters $c$ and $d$ with different compaction energies.

\begin{tabular}{lcc}
\hline Compaction energy & $c$ & $d$ \\
\hline$E_{0}=592.2 \mathrm{~kJ} / \mathrm{m}^{3}$ & 0.835 & -8.859 \\
$E_{1}=743.8 \mathrm{~kJ} / \mathrm{m}^{3}$ & 0.535 & -7.15 \\
$E_{2}=1420.8 \mathrm{~kJ} / \mathrm{m}^{3}$ & 0.417 & -6.23 \\
$E_{3}=2169.0 \mathrm{~kJ} / \mathrm{m}^{3}$ & 0.318 & -5.62 \\
\hline
\end{tabular}

Note. The values of $c$ and $d$ in the table are based only on this test.

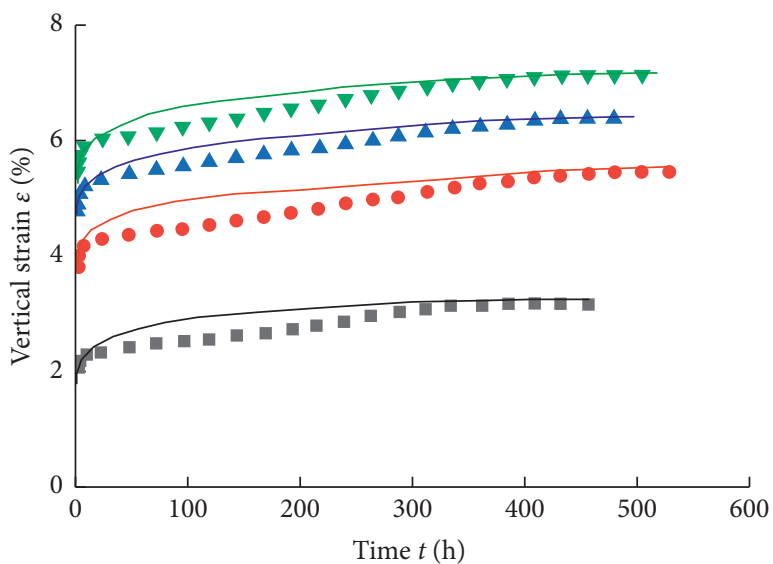

- $500 \mathrm{kPa}$

- $1000 \mathrm{kPa}$
A $1500 \mathrm{kPa}$

จ $2000 \mathrm{kPa}$

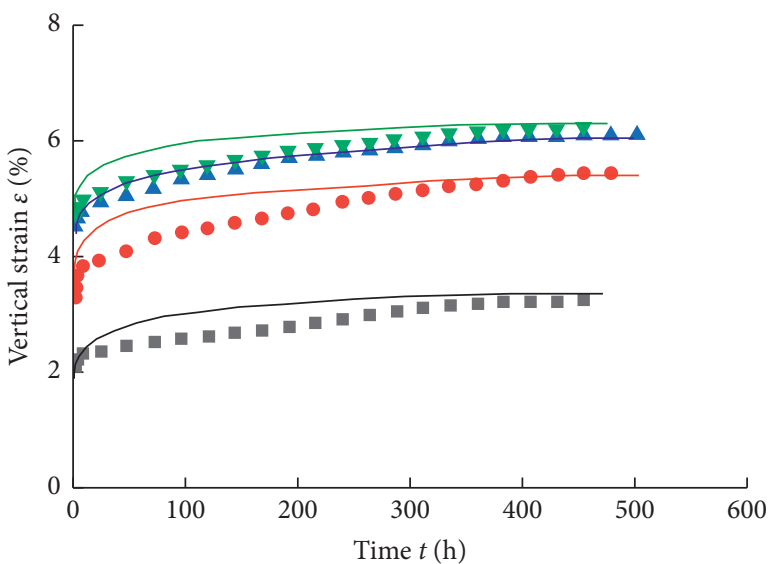

- $500 \mathrm{kPa}$

- $1000 \mathrm{kPa}$

- $1500 \mathrm{kPa}$

₹ $2000 \mathrm{kPa}$

(a)

(b)

FIgURe 11: Continued. 


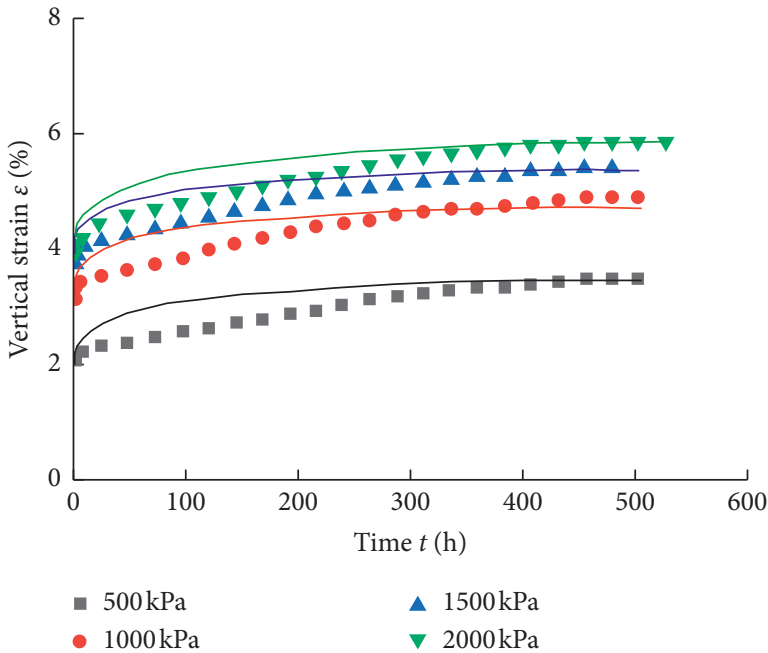

(c)

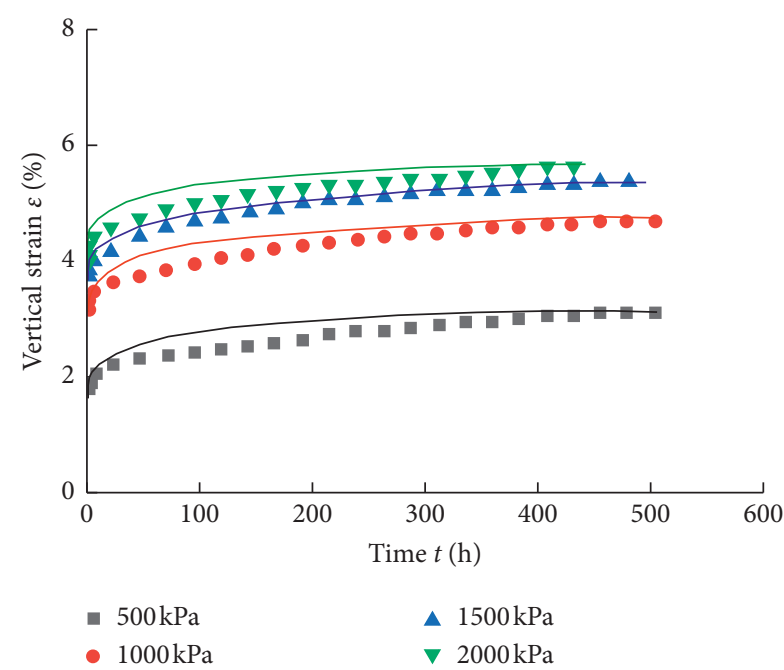

(d)

FiguRE 11: Comparison of calculation results and test results. (a) $E_{0}=592.2 \mathrm{~kJ} / \mathrm{m}^{3}$. (b) $E_{1}=743.8 \mathrm{~kJ} / \mathrm{m}^{3}$. (c) $E_{2}=1420.8 \mathrm{~kJ} / \mathrm{m}^{3}$. (d) $E_{3}=2169.0 \mathrm{~kJ} / \mathrm{m}^{3}$.

\section{Conclusions}

This study conducted a one-dimensional consolidation test on Yan'an compacted loess and analyzed the effects of compaction energy and consolidation pressure on the secondary consolidation characteristics. A prediction model for loess settlement considering different compaction energies and different fill thicknesses was proposed, and the model was further verified. The main conclusions are presented as follows:

(1) The strain-time curve with different compaction energies and different vertical stress was refined, and the strain-time curve within $2 \mathrm{~h}$ was obtained. The primary and secondary consolidations separation was conducted; the boundary time point between the primary and secondary consolidations was approximately 39 60 $\mathrm{min}$.

(2) Through analysis on the relationship between the secondary consolidation $\ln (\varepsilon / t)$ and $\ln (t)$, an expression is obtained after fitting. Based on the test results, a model expression describing the secondary consolidation deformation characteristics of loess with different compaction energies was obtained.

(3) The prediction model proposed in this study exhibits a slightly greater initial error in predicting settlement; however, the deviation gradually decreases with time. The prediction model generally well reflects the test results, thus showing an obvious advantage in guiding the design and construction of the loess filling project.

The prediction model proposed in this study does not incorporate the influence of moisture content and compactness on the long-term postconstruction settlement of the high-fill project; this will be studied in future research.

\section{Data Availability}

The data used to support the results of this study are included within the article.

\section{Conflicts of Interest}

The authors declare that there are no conflicts of interest.

\section{Acknowledgments}

This research was funded by the National Natural Science Foundation of China (41672305) and the Key Research and Development Program of Shanxi Province (2020SF-431).

\section{References}

[1] L. Bjerrum, "Engineering geology of norwegian normallyconsolidated marine clays as related to settlements of buildings," Géotechnique, vol. 17, no. 2, pp. 83-118, 1967.

[2] S. Murayama, K. Michihiro, and T. Sakagami, "Creep characteristics of sands," Journal of the Japanese Society of Soil Mechanics \& Foundation Engineering, vol. 24, no. 2, pp. 1-15, 1984.

[3] C. B. Crawford, State of the art; evaluation and interpretation of soil consolidations tests, ASTM special technical publication, vol. 892, Chicago. IL, USA, 1986.

[4] Z. Z. Yin, H. B. Zhang, J. G. Zhu et al., "Secondary consolidation of soft soil," Journal of Geotechnical Engineering, vol. 25, no. 5, pp. 521-526, 2003.

[5] Y. B. Gao, H. H. Zhu, G. B. Ye et al., "Experimental study on the ca value of one-dimensional secondary consolidation coefficient of saturated soft clay," Journal of Geotechnical Engineering, vol. 26, no. 4, pp. 460-462, 2004.

[6] Q. J. Zhou and X. P. Chen, "Experimental study on creep characteristics of soft soil," Journal of Geotechnical Engineering, vol. 28, no. 5, pp. 626-629, 2006. 
[7] G. X. Mei and J. H. Yin, "Coupled model of consolidation and creep for consolidation test," Journal of Central South University of Technology, vol. 15, no. 1, pp. 357-361, 2008.

[8] Z. Y. Yin, D. M. Zhang, P. Y. Hicher, and H. W. Huang, "Modelling of time-dependent behaviour of soft soils using simple elasto-viscoplastic model," Chinese Journal of Geotechnical Engineering, vol. 30, no. 6, pp. 880-888, 2008.

[9] D. W. Taylor and W. Merchant, "A theory of clay consolidation accounting for secondary compression," Journal of Mathematics and Physics, vol. 19, no. 1-4, pp. 167-185, 1940.

[10] P. L. Newland and B. H. Allely, "A study of the consolidation characteristics of a clay," Géotechnique, vol. 10, no. 2, pp. $62-74,1960$.

[11] G. Mesri and P. M. Godlewski, "Time- and stress-compressibility interrelationship," Journal of the Geotechnical Engineering Division, vol. 103, no. 5, pp. 417-430, 1977.

[12] S. Leroueil, M. Kabbaj, F. Tavenas, and R. Bouchard, "Stressstrain-strain rate relation for the compressibility of sensitive natural clays," Géotechnique, vol. 35, no. 2, pp. 159-180, 1985.

[13] E. E. Alonso, A. Gens, and A. Lloret, "Precompression design for secondary settlement reduction," Géotechnique, vol. 50, no. 6, pp. 645-656, 2000.

[14] D. Nash, "Precompression design for secondary settlement reduction: discussion," Géotechnique, vol. 51, no. 9, pp. 822-826, 2001.

[15] F. Goktepe, A. J. Omid, and E. Celebi, "Scaled soil-structure interaction model for shaking table testing," Acta Physica Polonica A, vol. 132, no. 3, pp. 588-590, 2017.

[16] M. M. Ge, N. Li, J. G. Zheng, C. H. Zhu, and Y. Y. Bo, "Postconstruction settlement prediction of high fill considering loess aging deformation characteristics," Journal of Civil Engineering, vol. 48, no. S2, pp. 262-267, 2015.

[17] J. Xu, Y. Li, S. Wang, Q. Wang, and J. Ding, "Shear strength and mesoscopic character of undisturbed loess with sodium sulfate after dry-wet cycling," Bulletin of Engineering Geology and the Environment, vol. 79, no. 3, pp. 1523-1541, 2020.

[18] J. Xu, Y. Li, C. Ren, and W. Lan, "Damage of saline intact loess after dry-wet and its interpretation based on SEM and NMR," Soils and Foundations, vol. 60, no. 4, pp. 911-928, 2020.

[19] J. Xu, Y. F. Li, C. Ren, S. H. Wang, S. K. Vanapalli, and G. X. Chen, "Influence of freeze-thaw cycles on microstructure and hydraulic conductivity of saline intact loess," Cold Regions Science and Technology, vol. 181, Article ID 103183, 2021.

[20] D. F. T. Nash, G. C. Sills, and L. R. Davison, "One-dimensional consolidation testing of soft clay from Bothkennar," Géotechnique, vol. 42, no. 2, pp. 241-256, 1992.

[21] A. Augustesen, M. Liingaard, and P. V. Lade, "Evaluation of time-dependent behavior of soils," International Journal of Geomechanics, vol. 4, no. 3, pp. 137-156, 2004.

[22] J. Sun, Geotechnical Material Rheology and Engineering Application, China Construction Industry Press, Beijing, China, 1999.

[23] X. J. Yu, Z. Z. Yin, and W. J. Dong, "Influence of load on secondary consolidation deformation of soft soils," Chinese Journal of Geotechnical Engineering, vol. 29, no. 6, pp. 913916, 2007.

[24] C. H. Zhu, "Study on settlement law of airfield high fill on deep loess foundation," Xi'an University of Technology, vol. 27, no. 4, pp. 392-399, 2011. 